\title{
Barroco: o grande dispositivo comunicacional na formação da identidade brasileira
}

\section{Baroque: the great communication device in the formation of Brazilian identity}

Déia Francishetti ${ }^{1}$ Gustavo de Castro ${ }^{2}$
1 Délcia Silva Francischetti, publicitária, mestranda do Programa de Pós-graduação da Universidade de Brasília, professora de História da Arte, Estética e Comunicação de Massa e Fundamentos da Linguagem Visual, supervisora pedagógica dos cursos de Jornalismo e de Publicidade e Propaganda do Centro Universitário de Brasília (UniCEUB).

2 Gustavo de Castro, $\mathrm{PhD}$ pela Universidade de Brasília, poeta, jornalista, escritor, editor e professor de estética. Atua nos limites entre Arte, Filosofia, Antropologia e Comunicação. Investiga a relação da poesia com a mídia. Estuda a beleza e o feio no Brasil: imaginários, complexidades e sensibilidades. O corpo, o erótico, a sensualidade, a viscosidade, a performance, o sonho, a fantasia, a transcendência, o feio, o brega, o grotesco e o escatológico.

\section{Resumo}

O objetivo deste artigo é propor uma reflexão sobre o papel do Barroco como linguagem autônoma fundamentada na imagem, capaz de, por meio dos componentes estilísticos, sentido de ordem e conceito, configurar a identidade cultural do Brasil do século XXI. De conteúdo doutrinário, a arte barroca foi utilizada como dispositivo comunicacional, uma ferramenta estratégica de subjetivação do indivíduo que viria a se tornar o brasileiro, atendendo aos objetivos colonizadores europeus, tendo como referência a experiência promovida pela Igreja Católica durante a Contrarreforma.

Palavras-chave: Barroco. Dispositivo comunicacional. Identidade cultural. Linguagem visual.

\begin{abstract}
The purpose of this article is to propose a reflection on the role of Baroque while autonomous language based on image able to, through the stylistic components, sense of order and concept, configure the cultural identity of 21ST-century Brazil. Doctrinal content, Baroque art was used as a communicational device, a strategic tool of subjectivation of the individual who would later become the Brazilian, taking into account the objectives European settlers, having as reference the experience promoted by the Catholic Church during the Counter-reformation.
\end{abstract}

Keywords: Baroque. Communication device. Cultural Identity. Visual Language.. 


\section{Introdução}

É possível identificar componentes estéticos usados pela comunicação de massa, no Brasil do século XXI, cujos referenciais visuais coincidam com aqueles presentes na arte barroca?

A princípio, considerando nossa jornada histórica e seus resultados no campo da expressão, essa pode parecer uma questão óbvia. No entanto, procuramos as razões pelas quais esse diálogo estético foi possível. Um diálogo voltado para algo maior, mas sempre presente em nossa memória mais longínqua e, por outro lado tão perto, personificado nas identificações do povo brasileiro que encontra nos referenciais barrocos uma linguagem universal, patente nas mais diversas manifestações culturais do nosso país.

Para tanto, compreender o Barroco do século XVI apenas como base da estética que resultou na Arte Colonial Brasileira não é o bastante. É preciso observá-lo com outro olhar, considerando-o nos contextos históricos que precedem e sucedem o descobrimento do Brasil até a atualidade; como conceito inserido não só nas "Belas Artes", mas também nas "Artes Aplicadas"; na qualidade de recontextualizações que o tenham considerado na contemporaneidade. Encontra-se em Santaella um estímulo. Para ela, alimentar separatismos pode levar a perdas tanto para as artes quanto para a comunicação no que se refere às possíveis convergências entre ambas. Nesse caso, a primeira fica "[...] limitada pelo olhar conservador que leva em consideração exclusivamente a tradição de sua face artesanal" e a segunda "[...] porque fica confinada aos estereótipos da comunicação de massa”. (SANTAELLA, 2008, p. 7).

Outra questão primordial é chegar a algumas conclusões sobre o significado, as características e o alcance de um dispositivo, com o intuito de verificar a aplicação desse conceito ao barroco como meio para a objetivação de uma comunicação intencionalmente subjetivadora, ou seja, um dispositivo comunicacional, ${ }^{3}$ empregado pelos conquistadores e pela Igreja, forte o bastante para forjar nossa identidade.

Dessa forma, inicialmente, precisaremos de al-

3 No âmbito desta pesquisa, a expressão "dispositivo comunicacional" será atribuída ao Barroco com o propósito de referenciá-lo como linguagem autônoma e funcional desvinculada da língua, da fala e da escrita, usada como meio e recurso na transmissão intencional de conceitos e ideias por meio da construção da imagem. guns esclarecimentos acerca desse barroco multifacetado, uma entidade conceitual tão protestante quanto católica, forte o suficiente para subjetivar, em nome de Deus, os filhos do casamento entre uma nação vermelha aqui sedimentada, uma negra para cá contrabandeada e uma branca ambiciosa, porém crédula e temente.

A profusão de documentos de áreas distintas e a grandiosidade do acervo Barroco no Brasil, e daquele resultante de sua influência, constituíram-se em elementos motivadores para o entendimento das condições, repercussões e razões que fizeram deste estilo e conceito as mais representativas formas de nossa expressão.

A opção por analisar tal bagagem ocorre pela percepção de que há uma identificação natural, quase ancestral, do brasileiro com seus elementos. Um diálogo contemporâneo que mesmo na pós-modernidade consegue interagir com quinhentos anos de expressão miscelânea, consolidando essa identidade intercultural do Brasil do século XXI.

\section{Barroco e barroco: esclarecimentos prelimi- nares}

A terminologia atualmente aplicada a vários movimentos e estilos artísticos só lhes foi atribuída posteriormente à sua vigência quando historiadores, críticos e estudiosos do campo das artes tiveram a isenção e o distanciamento necessários para uma apreensão mais precisa de suas características referenciais, criando, assim, denominações mais esclarecedoras de suas intenções expressionais e os "ismos", sufixo empregado na nomenclatura de estilos e escolas de arte a partir do Neoclassicismo. No caso do Barroco, não existem textos que se refiram a ele por meio da atual designação até a primeira metade do século XVIII, quando o termo passa a referi-lo como um estilo considerado confuso e exagerado em relação ao conceito clássico renascentista, demonstrando, com isso, um juízo de valor.

A partir da era moderna, a palavra barroco passa a ser usada democraticamente como sinônimo de engano (italiano: barochio), bizarro, esquisito e rebuscado, ou de forma pejorativa para designar algo ridículo, extravagante, grosseiro, pouco intelectualizado, popular. De origem grega (barros: pesado), em português denomina rochedo ou pérola irregular, barranco, cova, local barrento.

Atualmente, no Brasil, é empregado como gíria para se referir a algo tosco, rústico, inculto e de mau gosto. Ou ainda ao "brega", rótulo que relaciona estratos conceituais considerados cafonas da arte brasileira, como é 
o caso do gênero musical originário da região norte do país, extremamente sentimental e romântico, provavelmente nascido na zona do baixo meretrício, local que curiosamente é também denominado de barroco.

A ocorrência do termo "brega" em enunciados que se fundamentam a partir da caracterização de canções ou artistas musicais, quando relacionada ao funcionamento discursivo decorrente de determinados parâmetros classificatórios que abarcam os chamados "estilos musicais", evidencia a emergência de um paradigma bastante análogo àquele concernente ao kitsch no interior da arte contemporânea, conforme teorizado pelo filósofo Abraham Moles em sua obra intitulada $\mathrm{O}$ kitsch, material citado com certa recorrência em estudos literários, sociológicos, artísticos. (KHALIL, 2012, p. 136).

O interessante é que nenhuma dessas aplicações se refere à soberba, à religião, a uma intelectualidade afetada, a um gosto pretensamente refinado ou a uma classe social privilegiada. Mas sim à lembrança que remete à terra, ao mundano, à paixão e à sensualidade, à autenticidade, ao povo, ao popular, à realidade e à fé. Enfim, ao dilema humano que vem se formando do próprio barro. Dilema esse, restituído à arte.

Segundo Gombrich (1999) e Hauser (2000), o Barroco não se constituiu como movimento, não passando de um estilo proveniente do Renascimento, ao qual sucedem o Maneirismo, ele próprio e o Rococó. No entanto, é indispensável esclarecer que, a priori, a expressão se fundamenta em três elementos: "estilo", que é um traço pessoal inspirado numa "complexa fecundação cruzada de influências e movimentos artísticos"; "forma", referente a um "senso inato de organização" por meio de componentes estéticos e compositivos como, por exemplo, equilíbrio, proporção e unidade; e "conteúdo", relativo aos "objetivos na comunicação de ideias", conceitos e intenções das narrativas e poéticas. (HULBURT, 2002).

No que se refere ao estilo e à forma, as quatro expressões citadas são similares. Por isso, grande parte daquilo que hoje rotulamos de Barroco, na verdade, trata-se de Maneirismo, assim como o que denominamos de Rococó é Barroco. A diferença está nas subjetividades produtoras e resultantes desses rótulos em contextos históricos específicos, considerando os conteúdos característicos dos períodos em que se manifestaram.

\section{Renascimento}

O Humanismo Renascentista representou um novo homem, ciente do seu papel como sujeito principal de um mundo europeu em meio a revoluções científicas, que conferiram a ele "[...] a faculdade e as capacidades para inquirir, investigar e decifrar os mistérios da Natureza”. (HALL, 2005, p. 26).

O divino e o sobrenatural, inacessíveis do início da era Cristã ao final da Idade Média, incorporam, no início da Era Moderna, a imagem desse homem matematicamente inserido na proporção ideal, um resgate davinciano do legado de Vitrúvio, arquiteto romano do século I a.C. Como resultado, surgem novos questionamentos sobre a unidade e a beleza perfeita, sobre a própria existência, sobre as origens do ato de crer, e um novo olhar sobre o significado e a amplitude da fé.

\section{Maneirismo}

Distingue-se do Barroco pelas "poucas inserções na história” " “...] Sua forma e seu conteúdo encerram exatamente aquilo que entre os anos de 1520 a 1650 um pintor ou literato europeu deveria ressaltar para ser chamado de moderno". Materializou interpretações individuais, salientando "[...] o fantástico, o ambíguo, a metáfora obscura, a alusão, o engenho e o sofisma”. (HOCKE, 1974, p.1617). Destacou a ação ou a inércia e a angulação, propondo uma reação intelectual e novos pontos de vista.

\section{Barroco}

Acima de tudo, designa um momento histórico de grandes questionamentos existenciais e quebra de paradigmas. Antagônico por excelência, nasce na modernidade estética e conceitual, preparada "[...] em grande extensão pela Renascença e pelo Maneirismo". Segundo Hauser, o Barroco "[...] engloba tantas ramificações do esforço artístico, apresenta-se em formas tão diferentes de país para país e nas várias esferas de cultura, que à primeira vista parece duvidoso que seja possível reduzi-las a um denominador comum." (HAUSER, 2000, p. 442-445).

Foi apresentado ao Novo Mundo com um conteúdo ideológico e doutrinário, destinado a propagar a Contrarreforma Católica e a superar as barreiras linguísticas e culturais entre conquistadores e conquistados. Nesse contexto, resultou numa arte ousada, proselitista e eminentemente funcionalista, como categoria estilística.

No Brasil, assume o rótulo de Arte Colonial, termo abrangente que denomina a arte produzida em várias regiões entre os séculos XVI e XVII, resultado da mistura das expressões dos povos envolvidos nos processos díspares de colonização e evangelização; dos referenciais 
étnicos de beleza; das intenções sociais, políticas e econômicas; da geografia e das riquezas das regiões onde as colônias foram implantadas; das possibilidades comerciais dessas colônias como, por exemplo, a extração de ouro em Ouro Preto, Minas Gerais, e a troca desse ouro por prata, metais utilizados na arte sacra.

\section{Rococó}

A partir do século XX, passa a ser visto como um movimento de características próprias e não como um estilo. Reflete a "[...] atitude natural de uma sociedade frívola, cansada e passiva que se volta para a arte em busca de prazer e repouso". (HAUSER, 2000, p. 529).

Mundano, leve, sutil, rebuscado e ornamentalista, o Rococó se manifestou na arquitetura, na decoração, nas artes gráficas e industriais e na moda durante o século XVIII. Foi a última manifestação artística reconhecida como um estilo universal no mundo ocidental "civilizado”. O Brasil é o único país onde esta arte contempla temas religiosos, sendo aplicada principalmente na arquitetura. Aleijadinho e Mestre Ataíde, pintores, escultores e arquitetos são destaques importantes. Além de somarem Barroco e Rococó na representação de temas religiosos, deixaram evidente em suas obras a preferência pelos referenciais estéticos resultantes da mestiçagem étnica e pela exuberância da paleta de cores brasileira.

Por outro lado, podemos identificar características do barroco como conceito nas cinco categorias estilísticas utilizadas com o propósito de encontrar pontos de associação entre "produtos das artes e dos ofícios visuais ao longo da história”. São elas: primitivista, expressionista, clássica, ornamentalista e funcionalista. Assim podemos encontrar numa única obra barroca ou em qualquer outro estilo, simultaneamente, referenciais de todas essas categorias. Ou ainda podemos incluir, numa mesma categoria, obras distanciadas entre si por séculos. (DONIS, 2003, p. 161-181).

Tais categorias foram criadas a partir da observação e do entendimento daquilo que compõe o estilo, item de extrema relevância na avaliação da expressão, tendo em vista que o estilo aponta e revela o indivíduo na condição de sujeito, capaz de se agregar a outros indivíduos, arquitetos da própria cultura que se caracteriza e, consequentemente, se identifica, perante outras tantas, como única. Raymond Williams observa que a história moderna desse sujeito o apresenta com características particulares: a do ser "indivisível” - uma entidade que é unificada no seu próprio interior e não pode ser dividida, e a de uma entidade que é "singular, distintiva, única". (HALL, 2003, p. 25)

Assim como no Expressionismo, no Futurismo ou no próprio Barroco, cada qual em seu tempo de abrangência, ou quando da apropriação dos seus referenciais estéticos e conceituais nos séculos e décadas que os sucederam até a atualidade, podemos perceber que, em qualquer uma das situações, a escolha pelo uso periódico de componentes estilísticos constitui o que denominamos de tendência.

A tendência, por sua vez, reflete a construção expressional, ou seja, novamente o estilo que

[...] é a síntese última de todas as forças e fatores, a unificação, a integração de inúmeras decisões e estágios distintos. No primeiro nível está a escolha do meio de comunicação, e a influência deste sobre a forma e o conteúdo. Depois vem o objetivo [...]: sobrevivência, comunicação, expressão pessoal. (DONDIS, 2003, p. 166).

Portanto, o estilo é baseado em elementos como: personalidade e preferências pessoais, padrão de beleza familiar, sensibilidade, percepção, intenção pessoal, momento de vida, cultura, religião, crença, filosofia, localização geográfica, referências estéticas quanto à fauna e à flora, clima, inspiração, finalidade básica, tecnologia disponível, intelectualidade, técnica aprendida, normas estilísticas, convenções culturais, opção político-ideológica, condicionamentos, embasamento estético, pesquisa estética e conceitual, materiais, suportes e veículos ou mídias disponíveis, momento histórico, intenção do patrocinador e mercado. A sua difusão pode resultar num estilo pessoal ou coletivo, como por exemplo, na moda. Pessoal, como podemos observar na comparação entre as obras de Andy Warhol e Roy Lichtenstein, pode culminar em uma nova tendência e gerar pesquisa coletiva, como no caso da Pop Art que, a despeito dos diversos estilos pessoais que a representam, propunha a cultura de massa como conteúdo. $\mathrm{O}$ estilo pessoal é sempre autoral, singular, original e é admitido como tal nas artes e na comunicação de massa. Assim, reconhecemos a Monalisa de Da Vinci (belas artes) e a Monalisa de Maurício de Souza (comunicação de massa) como diferentes em estilo, forma e conteúdo.

Estudando o barroco como arte e conceito por outro viés, Eugeni D’Ors “[...] chegou à conclusão que, do ponto de vista formal, poder-se-á apontar uma alternância entre o estilo 'barroco' e o estilo 'clássico', através de 
toda a história cultural da humanidade" (HOCKE, 1974, p. 18), ocorrência que considera, desde a pré-história, $B a$ rocchus Pristinus, como se, de alguma forma, um espírito barroco sempre precedesse os processos de inquietação, incorporando, posteriormente, na forma de um caldeirão de bruxa, depositário de todos os ânimos, vontades, imersões, vômitos, sonhos, desejos, pesadelos, censura e liberdade, ordenamentos e, enfim, santos, anjos e demônios na magna urgência de transmutar por meio da arte, num processo vivo, constante e conceitual. Como um éon, palavra derivada do termo grego aion, que significa era ou força vital. De caráter metafísico, os éons caracterizam um "desenvolvimento inscrito no tempo, de maneira histórica [...] representam nossas ideias-acontecimentos [...] são os sistemas em que conjugamos fenômenos distantes entre si, mas que discriminamos como contíguos". (SILVA, 2001, p. 40). Esses fenômenos contíguos D’Ors classificou como espécies, vinte e duas ao todo, pertencentes ao gênero Barocchus. Para ele, a Arte Colonial brasileira seria proveniente do Barocchus Tridentinus, sive Jesuiticus.

Segundo Hauser (2000), o desenrolar histórico e a consolidação do pensamento reformista atingiram drasticamente áreas como a política, a filosofia e a ciência, mudando comportamentos e pontos de vista. No que se refere ao mercado das artes, a cisão ocorreu nas mesmas proporções, na medida em que os patrocinadores já não mais compartilhavam da mesma ideologia. Nos países protestantes, a Igreja deixa de patrocinar a arte religiosa, obrigando os artistas a pintarem retratos e paisagens para o mecenato burguês.

A iconografia da arte da Igreja Católica obede-
ce a um esquema fixo: a Anunciação, o Nasci-
mento de Cristo, o Batismo, a Ascenção, a Via
Crucis, a Samaritana, o Cristo no Horto e mui-
tas outras cenas bíblicas adquirem a forma que
ainda hoje é válida como modelo padronizado
para a imagem votiva. (HAUSER, 2000, p. 454).

Isso demonstra claramente o uso da arte barroca como meio de comunicar e persuadir por meio da imagem, ensejando uma tomada de posição por parte dos fiéis ao seu favor. Assim, diante da diversidade de conceitos e propósitos expostos anteriormente, consideramos Barroco (grafado em caixa alta e baixa, ou ainda denominado como arte barroca) como dispositivo comunicacional, movimento e estilo nas artes plásticas, na música, na arquitetura, na moda, no cinema e na literatura; como parte de um panorama cultural, indispensável ao enten- dimento dos seus momentos históricos, manifestações e recontextualizações até a atualidade. Em caixa alta e baixa para gênero (Barocchus). Grafado em caixa baixa (barroco), na qualidade de conceito, com o intuito de ampliar a compreensão acerca dos desdobramentos políticos e filosóficos, decorrentes de suas influências, como território subjetivo na formação da identidade cultural brasileira.

\section{Garimpando}

Antes que nossa história começasse como nação, nossas terras já eram habitadas por povos unidos por dialetos provenientes de um mesmo tronco linguístico, espalhados em parte da Amazônia e quase todo o litoral brasileiro.

Segundo Darcy Ribeiro, em 1454, o Vaticano estabeleceu normas básicas para ação colonizadora da África, impondo, por exemplo, a bula Romanus Pontifex do papa Nicolau V, cujo teor dá ideia do que os habitantes, desse ainda nem Brasil, brevemente também enfrentariam em nome de Deus, com a chegada dos portugueses em seu território:

Não sem grande alegria chegou ao nosso conhecimento que nosso dileto filho infante D. Henrique, incendido no ardor da fé e zelo da salvação das almas, se esforça por fazer conhecer e venerar em todo o orbe o nome gloriosíssimo de Deus, reduzindo à sua fé não só os sarracenos, inimigos dela, como também quaisquer outros infiéis. Guinéus e negros tomados pela força, outros legitimamente adquiridos foram trazidos ao reino, o que esperamos progrida até a conversão do povo ou ao menos de muitos mais. Por isso nós, tudo pensando com devida ponderação, concedemos ao dito rei Afonso a plena e livre faculdade, entre outras, de invadir, conquistar, subjugar a quaisquer sarracenos e pagãos, inimigos de Cristo, suas terras e bens, a todos reduzir à servidão e tudo praticar em utilidade própria e dos seus descendentes. Tudo declaramos pertencer de direito in perpetuum aos mesmos D. Afonso e seus sucessores, e ao infante. Se alguém, indivíduo ou coletividade, infringir essas determinações, seja excomungado [...]. (BAIÃO 1939 apud RIBEIRO, 1995, p. 39-40)

Do ponto de vista eurocêntrico, vigente nos séculos XV e XVI, a história do Brasil começa com a sua “descoberta” por Pedro Álvares Cabral e sua esquadra, no dia 22 de abril de 1500. Foram recepcionados, majoritariamente, por Tupis, então uma "macroetnia" nunca unificada, com crença e costumes sedimentados, habitantes daquela terra por eles já ocupada e demarcada, da qual detinham valioso conhecimento sobre a fauna, a flora e 
suas aplicações medicinais. A princípio acreditou-se que “[...] somavam, talvez, um milhão de índios, divididos em dezenas de grupos tribais, cada um deles compreendendo um conglomerado de várias aldeias de trezentos a dois mil habitantes", ou seja, com aproximadamente o mesmo número de habitantes que Portugal naquela época. (RIBEIRO, 1995, p. 31).

Os portugueses logo visualizaram possibilidades de explorarem os potenciais humano e econômico local, consolidando mais uma conquista material para a Coroa. Tinham a seu favor não só o desconhecimento do suposto empate numérico entre seus habitantes, mas também armas poderosas, como a prepotência, a ciência, a varíola, o chicote, a arte barroca, a avançada tecnologia naval e bélica, a hostilidade, a intolerância, a ganância e o consentimento papal para subjugar todos os povos, principalmente os pagãos, em nome de uma doutrina reativa a uma reforma ameaçadora, "[...] definindo-se como expansores da cristandade católica sobre os povos existentes e por existir além-mar." (RIBEIRO, 1995, p. 39).

No entanto, o item de maior relevância nesse contexto refere-se à defasagem generalizada da condição evolutiva entre os personagens desta história. Por aqui, a população nativa vivia ainda a era neolítica, fase marcada pelo sedentarismo. Dentre as várias mudanças nesse período, destaca-se a revolução agrícola que possibilitava plantar e colher o próprio alimento e usar o excedente da produção como escambo; o homem descobre fascinado que faz parte da geração de outros seres humanos, o que expande o seu poder, promovendo o aumento da mão de obra e criando gradativamente a institucionalização das relações familiares, um mero dispositivo a serviço do poder.

Ainda entre as consequências, o início do processo filosófico permitiu a esse homem buscar o conhecimento por meio de mecanismos muito próximos aos do Racionalismo, em voga na Europa globalizante de Descartes. Dez mil anos à frente no processo evolutivo, o Racionalismo buscava o conhecimento por meio da razão, na qual a experiência e a dedução passaram a ser usadas como método sofisticado de investigação, configurando a corrente central do pensamento liberal.

Assim, adiante a essa intrincada e controversa "descoberta" e posterior "colonização" do Brasil, do ponto de vista econômico, tinha início a corrida à Ilha de Vera Cruz por povos interessados no comércio e no consequente aumento de capital para as suas burguesias por meio, a princípio, do extrativismo. A intenção, que beirava à megalomania, era de se expandir e se unificar num mundo europeu. Não obstante, Ribeiro credita à defasagem evolutiva, ou mais precisamente ao "atraso dos índios", o fator que os forjou mais “[...] resistentes à subjugação, condicionando uma guerra secular de extermínio." (RIBEIRO, 1995, p. 49).

No decorrer dos séculos seguintes, essa realidade traria ainda para essas bandas, além de portugueses e africanos contrabandeados, povos de diferentes raças e etnias. Dessa forma, por meio das imigrações e consequente miscigenação, o Brasil se consolidou como uma nação miscelânea e intercultural.

O mais interessante é que todos os povos oriundos desse processo foram, naquele momento, envolvidos num conceito barroco de viver: de um lado o branco trazia a "salvação" e um poder excepcional de convencimento; para ele, a Contrarreforma representava, naquele cenário de fortalecimento da crença, a possibilidade da formação de um novo sujeito, ou seja, de um novo processo de "subjetivação" lucrativo tanto para a Igreja quanto para a Coroa, um dos fenômenos marcantes da era moderna. De outro, índios e posteriormente negros africanos passaram a vivenciar um processo de "dessubjetivação", não pela própria "negação do eu", mas por não ter acesso à "recomposição de um novo sujeito" naquele contexto alienígena. (AGAMBEN, 2009, p. 47).

As possibilidades que o campo da história oferece para a compreensão de uma situação tão singular, vivida simultaneamente por conquistadores e conquistados, fazem parte, em níveis diferentes, do mesmo processo dedutivo e transformador que, embora similares, deixava claro, naquele contexto, os diferentes ou divergentes diálogos possíveis numa relação entre "pais" (os conquistadores modernos) e "filhos" (os conquistados neolíticos). Ou seria o contrário?

Seria necessário passarmos por um processo alienante de aculturação para, só assim e a partir de então, construirmos a identidade brasileira.

\section{Barroco: o grande dispositivo}

O Barroco, sem dúvida, foi um dos mais importantes dispositivos comunicacionais empregados como meio e linguagem, quando dos primeiros contatos entre as etnias que construíram a base do que hoje se configura como a cultura brasileira.

Feito inicialmente por padres e jesuítas, posterior- 
mente ainda por colonos e missionários, constitui-se em um espetáculo que impressiona, pela característica e o aspecto funcional, devido à facilidade de comunicar suas intenções a culturas distintas e com características diversas. Representa uma visão de mundo menos heterogênea, pois expressa o resultado da união entre os componentes formais originários da Europa e as características estéticas referenciais das localidades e colônias por onde foi propagado.

Por meio dessa liberdade construtiva, o Barroco se potencializou e ganhou uma dimensão mais dramática do que a representada na arte pictórica, na literatura, na música e, principalmente, na arquitetura simples e na opulenta decoração dos interiores das igrejas. Amparado por uma estratégia de poder, o Barroco se constituiu numa nova fórmula de mediação: um alfabeto ideográfico e imagético composto por sinais, cores, sombras e luzes, perspectivas, movimento, formas e conteúdos convencionados, necessários à interpretação dos discursos entre partes distintas, conquistadores e conquistados. Essa fórmula foi empregada em todos os níveis e aspectos, e em todas as localidades por onde foi propagada ou empregada como tendência das artes nas regiões dominadas, quando das conquistas territoriais por europeus que, no século XVI, davam os primeiros passos rumo ao que entendemos atualmente, guardadas as devidas proporções, por globalização. Um missionário, com as soluções e os arranjos artísticos, atuando como elemento persuasivo e doutrinário de povos que, por vezes, adoravam o sol, atribuindo a ele poderes divinos, e que nem de longe suspeitavam da então recente teoria heliocêntrica de Copérnico.

Severo Sarduy, em seu livro sobre o barroco, afirma que esse movimento está sempre associado a momentos de crises epistemológicas, quando valores perenes - principalmente no campo da astrofísica - em que se baseiam os sistemas políticos, as crenças e as religiões são abalados por novas descobertas, como a não centralidade da Terra no sistema solar, a relatividade do tempo e do espaço ou a efemeridade do universo. O barroco é expressão de momentos em que falta à humanidade solo firme para pisar. (MACHADO, 2010, p. 75).

No que se refere à ação doutrinária, esta teve origem na guerra entre jesuítas e calvinistas. Em resposta à Reforma Protestante, a Igreja buscava (para usar um termo muito empregado pelo marketing contemporâneo) "prospectar novos clientes" nesta "praça" ainda inexplorada chamada América. Nesse contexto, particu- larmente os potenciais “clientes" da Terra de Santa Cruz (índios e posteriormente negros africanos) careciam de um intérprete, e os colonizadores, por sua vez, de uma comunicação composta por elementos emocionalmente expressivos e universalmente compreensíveis, capazes de superar as enormes barreiras linguísticas e culturais entre as partes.

Rompendo o equilíbrio entre a razão e o sentimento, a arte barroca afastou-se da racionalidade que norteara os artistas renascentistas, apelando para elementos opostos e complementares, objetivando intenções e provocando uma atitude reflexiva diante da grandeza e da exuberância daqueles conteúdos antagônicos.

No entanto, que poder teria o Barroco não só na seara das artes, mas como meio de comunicação entre etnias distintas, díspares em seus interesses, capaz de revolver o imaginário e promover um diálogo entre milhares de personagens que figurariam, então, como arquitetos da base cultural do que é hoje o Brasil?

O Barroco reverberou além de um método ou uma mera influência. Seria preciso "uma revolução messiânica entre o mundo profano e o mundo messiânico" e um processo de "subjetivação" para adquirirmos esse jeito barroco que nos é tão característico. (BENJAMIN, apud AGAMBEN, 2009, p. 10).

Assim, quando da violenta cisão inicial e posterior confluência das várias culturas participantes da formação identitária brasileira, a arte barroca foi empregada como dispositivo de instrução e ajuste, resultando num conceito notório, num traço marcante em nossas relações e produções.

O termo "dispositivo" empregado para destacar os elementos formais utilizados na arte barroca, com a intenção de persuadir e moldar por meio da comunicação, é o termo de que nos apropriamos com base na genealogia de Agamben, que encontra nas pesquisas de Foucault aquilo a que este viria a denominar de "governabilidade" ou de "governo dos homens". (FOUCAULT, 1977 apud AGAMBEN, 2009, p. 27).

No ensaio "O que é um dispositivo?", Agamben menciona uma entrevista concedida por Foucault em 1977, nesta chamou-nos a atenção a percepção foucaultiana no tocante ao "tanto o dito como o não dito", como se pode observar no trecho a seguir.

[...] dispositivo é um conjunto absolutamente heterogêneo que implica discursos, instituições, estruturas arquitetônicas, decisões regulamentares, leis, medidas administrativas, enunciados 
científicos, proposições filosóficas, em resumo: tanto o dito como o não dito, [...] é a rede que se estabelece entre estes elementos [...] de estratégias de relações de força que condicionam certos tipos de saber e por eles são condicionados. (FOUCAULT, 1977 apud AGAMBEN, 2009, p. 27)

Buscando o termo "dispositivo" em um contexto histórico mais amplo, Agamben, que mais tarde o usaria para denominar mecanismos de jogos de poder, encontra o termo positivité, usado por Foucault ao final dos anos de 1970, com base no ensaio de Jean Hyppolite "Introdução à filosofia da história de Hegel” (HYPPOLLITE, 1948 apud AGAMBEN. 2009, p. 30). Nele Hegel diferencia "religião natural" de "religião positiva". Para ele, a religião natural refere-se às relações humanas com o divino, enquanto que a religião positiva compõe-se de uma série de ritos e regras impostos ao indivíduo, num determinado período histórico e sociedade específica, e "[...] implica em sentimentos que vêm impressos nas almas por meio da coerção e comportamentos que são o resultado de uma relação de comando e obediência e que são cumpridos". Refere-se, ainda, à religião como um estado social coercivo e limitante da liberdade humana. Mais tarde "positividade" se tornará "dispositivo" com um conceito ampliado e diferentes significados. (HYPPOLLITE, 1948 apud AGAMBEN, 2009, p. 30-31).

\section{A força da Trindade}

Entre o segundo e o sexto século, a Igreja passou a discutir as figuras do Pai, do Filho e do Espírito, uma Trindade de figuras divinas. Temendo por seu enfraquecimento com a consequente volta do politeísmo, a Igreja criou um discurso com base no termo grego oikonomia (administração do oikos - casa) no qual Deus confiava a administração do seu rebanho a Cristo, seu filho, introduzindo assim um poderoso dispositio na fé cristã.

Assim, nove séculos depois, a Contrarreforma contaria com a força da Trindade, com o aperfeiçoamento daquele dispositivo e, ainda, com as figuras dos jesuítas e mais adiante dos missionários destinados a pastorear o rebanho de hereges e de pagãos no novo mundo, o que não é pouca coisa, pois demonstra a instituição da práxis ${ }^{4}$ no governo divino.

Para Agamben, "o termo dispositivo nomeia aquilo que e por meio do qual se realiza uma pura atividade

4 Práxis: grego prâksis, -eos, acção, transação, negócio. de governo sem nenhum fundamento no ser. Por isso, os dispositivos devem sempre implicar num processo de subjetivação, isto é, devem produzir o seu sujeito". (AGAMBEN, 2009, p. 38).

Por sua vez, Félix Guattari (1996) conclui que não é natural à essência humana proporcionar ao homem uma forma de vida permanentemente prevista e organizada. Para ele a subjetivação é o processo vivencial contínuo, comunicante e comunicável, que produz nesse ser humano o sujeito que passa a viver de acordo com mudanças impostas por outrem, sendo a subjetividade "[...] essencialmente fabricada e modelada no registro social" e, portanto, não "[...] passível de totalização ou de centralização no indivíduo". (GATTARI; ROLNIK, 1966, p. 31). Assim, o sujeito é sempre um construtor coletivo e dinâmico de subjetividades como resultado temporário de um processo de subjetivação. Um fluxo participante na formação da identidade coletiva por meio da troca de informações. O sujeito é o produtor da subjetividade, é a probabilidade, é o $E s e$ ?, é o questionamento que se impõe e dá origem ao dispositivo e ao processo de subjetivação. O sujeito é o produtor permanente da organização e, portanto, da previsibilidade.

É preciso ressaltar que tais processos ocorrem em contextos históricos específicos e se manifestam diferentemente, assim como os processos filosóficos, pois tanto um quanto o outro dependem do problema questionador. Este, por sua vez, é condicionado por inúmeras variantes como, por exemplo, os valores, as convenções impostas e legitimadas institucionalmente ou, ainda, a defasagem na condição evolutiva dos personagens envolvidos.

Embora seja induzida ou imposta em alguns casos, como vimos anteriormente, a subjetivação é sempre uma opção individual do sujeito, o que a caracteriza como tal; e as condições que alicerçam a sua admissão, enquanto processo ou resultado, também podem estar presentes na ética, na configuração social, na religião ou na tradição comunitária, entre outros. Atualmente podemos considerar ainda a tecnologia, a mídia, o capital disponível, a sala de aula e uma infinidade de outros agentes dinâmicos inseridos em nossas condutas sociais. O seu resultado pode gerar um diálogo que dará continuidade ao processo transformador, provocando uma mudança de paradigma e configurando uma ruptura histórica.

Qualquer reforma religiosa, política e social passa pelo processo de subjetivação e resulta na reinvenção desses estratos. Assim crer, resistir, protestar, rotular e tantos 
outros verbos podem fazer parte de uma imensa lista de atitudes resultantes de processos de subjetivação.

Quando da formação do sujeito brasileiro, tanto por parte dos governantes quanto por parte da Igreja, não se produziu um estrato ou uma "classe dominante nativa". Segundo Ribeiro,

[...] no plano ideológico [...] a cultura das comunidades neobrasileiras se plasma sobre [...] elementos como a língua portuguesa, que se difunde lentamente $[. .$.$] até converter-se no ve-$ ículo único de comunicação das comunidades brasileiras entre si e delas com a metrópole; um minúsculo estrato social de letrados que [...] orienta as atividades mais complexas e opera como centro difusor de conhecimentos, crenças e valores; uma Igreja oficial, associada a um Estado salvacionista, que depois de intermediar a submissão dos núcleos indígenas através da catequese impõe um catolicismo de corte messiânico e exerce um rigoroso controle sobre a vida intelectual da colônia, para impedir a difusão de qualquer outra ideologia e até mesmo do saber científico; artistas que exercem suas atividades obedientes aos gêneros e estilos europeus, principalmente o barroco, dentro de cujos cânones a nova sociedade começa a expressar-se. (RIBEIRO, 1995, p. 75).

Nesse sentido, tanto como arte, estilo ou conceito, quanto como dispositivo comunicacional, o Barroco mudou a experiência do tempo, em especial do nosso tempo, servindo como um meio de subjetivação e ajuste desse novo mundo, formando aqui uma nação de sujeitos aos quais não restava outra opção que não a de considerar o $E$ se?. O resultado foi o brasileiro.

\section{Conclusão}

$\mathrm{Na}$ formação da identidade brasileira, o Barroco assumiu um papel preponderante, que vai muito além de suas expressões artísticas. Na verdade, seus componentes estéticos serviram como meio para a formulação de um discurso político-ideológico que visava facilitar o domínio europeu sobre as populações nativas e os demais povos incorporados ao processo produtivo da América Ibérica.

No Brasil, a grandiosidade do acervo barroco, um patrimônio incomensurável, resultou do uso sistemático desse tipo de expressão, um verdadeiro dispositivo comunicacional, capaz de permitir ao europeu, em nome de Deus, impor-se aos demais grupos étnicos, muito mais numerosos.

Apesar das divergências entre as diferentes correntes de estudiosos no que se refere à origem e ao al- cance do barroco, prevalece a ideia de que esse espírito conceitual sempre precedeu os momentos de inquietação e de quebra de paradigma ao longo da história da humanidade, como ocorreu durante a Contrarreforma, ocasião em que a arte barroca serviu para comunicar e persuadir. Nesse caso, fica fácil entender o papel de dispositivo comunicacional exercido por essa expressão.

No caso do Brasil, considerando os objetivos traçados pelos portugueses na exploração das riquezas aqui encontradas e as condições culturais dos povos que aqui habitavam, o Barroco mostrou-se particularmente eficiente como estratégia de aproximação e dominação, propiciando uma "subjetivação" baseada em valores essencialmente brancos e europeus.

Quer como arte, estilo ou conceito, ou como dispositivo comunicacional, o Barroco propiciou uma relação diferente com o tempo, especialmente com o nosso tempo. Por meio do Barroco, forjou-se na América portuguesa uma nação de sujeitos que incorporaram às suas experiências um modo barroco de ser.

\section{Referências}

AGAMBEN, Giorgio. O que é contemporâneo e outros ensaios. Chapecó, SC: Argos, 2009.

DONDIS, Donis A. Sintaxe da linguagem visual. 2. ed. São Paulo: Martins Fontes, 2003.

GUATTARI, F.; ROLNIK, S. Micropolitica: cartografias do desejo. Petrópolis, RJ: Vozes, 1996.

GOMBRICH, E. H. A história da arte. 16. ed. Rio de Janeiro: LTC, 1999.

HALL, Stuart. A identidade cultural na pós-modernidade. Rio de Janeiro: DP\&A, 2006.

HAUSER, Arnold. História social da arte e da literatura. São Paulo: M. Fontes, 2000.

HOCKE, Gustav René. Maneirismo: o mundo como labirinto. São Paulo: USP, 1972.

HULBURT, Allen. Layout: o design da página impressa. São Paulo: Nobel, 2002.

KHALIL, Lucas Martins Gama. A discursivização da música brega em paralelo com o conceito de kitsch. Porto Alegre: UFRGS, 2012. (Cadernos do IL, 44)

MACHADO, Arlindo. Arte e mídia. 3. ed. Rio de Janeiro: Zahar, 2010. 
PROENÇA, Graça. História da arte. 17. ed. São Paulo: Ática, 2007.

RIBEIRO, Darcy. O povo brasileiro. 2. ed. São Paulo: Companhia das Letras, 1995.
SILVA, Soraia M. Profetas em movimento. São Paulo: Edusp, 2001.

SANTAELLA, Lúcia. Por que as comunicações e as artes estão convergindo? 3. ed. São Paulo: Paulus, 2008. 